\title{
Usulan Perawatan Sistem Boiler dengan Metode Reliability Centered Maintenance (RCM)
}

\author{
Hamim Rachman*, Annisa Kesy Garside, Heri Mujayin Kholik \\ Jurusan Teknik Industri, Fakultas Teknik, Universitas Muhammadiyah Malang \\ Jl. Raya Tlogomas 246 Malang, 65144 \\ *Surel: hamimrachman@gmail.com
}

\begin{abstract}
Pembangkit Listrik Tenaga Uap (PLTU) PT Indo Pusaka Berau is a PLN work unit that provides electricity to consumers. The problem of the company is the frequent damage to boiler engine components. The company uses corrective maintenance system. On the problem, it is necessary to develop a machine maintenance system with Reliability Centered Maintenance (RCM) approach. The objective of the study was to select a boiler system maintenance action based on the RCM method and component replacement interval to minimize Total Minimum Downtime (TMD). Results of data processing RCM method, component in category Condition Directed (CD) is El Bow component. Components in Time Directed category (TD) are gland seal steam and check valve. Components in the Time Directed category are calculated for component replacement intervals on TMD criteria. The calculation result from component replacement interval was obtained 37 days for gland seal steam component and 58 days for check valve component. The proposed treatment of RCM method can reduce downtime by $11.33 \%$ of the company's maintenance methods.
\end{abstract}

Key Word: Corrective Maintenance, Downtime, RCM, Boiler, and TMD.

\begin{abstract}
Abstrak
Pembangkit Listrik Tenaga Uap (PLTU) PT. Indo Pusaka Berau merupakan unit kerja PLN yang menyediakan listrik kepada konsumen. Permasalahan perusahaan adalah sering terjadi kerusakan komponen mesin boiler. Perusahaan menggunakan sistem corrective maintenance. Berdasarkan permasalahan, perlu dilakukan pengembangan sistem perawatan mesin dengan pendekatan Reliability Centered Maintenance (RCM). Tujuan penelitian adalah memilih tindakan perawatan sistem boiler berdasarkan metode RCM dan interval penggantian komponen untuk meminimalisasi Total Minimum Downtime (TMD). Hasil pengolahan data metode RCM, komponen dalam ketegori Condition Directed (CD) yaitu komponen El Bow. Komponen dalam katagori Time Directed (TD) yaitu gland seal steam dan check valve. Komponen dalam katagori Time Directed dilakukan perhitungan interval penggantian komponen berdasarkan kriteria TMD. Hasil perhitungan interval penggantian komponen didapatkan 37 hari untuk komponen gland seal steam dan 58 hari untuk komponen check valve. Usulan perawatan metode RCM dapat menurunkan downtime sebesar $11,33 \%$ dari metode perawatan yang dilakukan perusahaan.
\end{abstract}

Kata Kunci: Corrective Maintenance,Downtime, RCM, Boiler, dan TMD.

\section{Pendahuluan}

Di zaman modern dan teknologi semakin maju kebutuhan energi akan selalu meningkat. Meningkatnya kebutuhan energi membuat konsumen listrik baik perusahaan atau industri kecil dan besar serta kebutuhan rumah tangga pun meningkat. PLN merupakan perusahaan pemerintah dalam menyediakan energi listrik yang dapat memenuhi kebutuhan konsumen dalam skala besar dan harus memiliki 
keandalan yang baik. Keandalan yang baik merupakan faktor yang perlu diperhatikan adalah sistem perawatan.

Perawatan (maintenance) adalah suatu kombinasi dari berbagai tindakan yang dilakukan untuk menjaga dan memelihara suatu mesin serta memperbaikinya sampai suatu kondisi yang bisa diterima [1,2]. Di mana nantinya kebutuhan listrik tidak mengalami kendala dalam distribusinya. Penelitian yang pernah dilakukan Prasetyo [3] pada PT XYZ perusahaan manufaktur yang memproduksi gula. Dalam penelitiannya terdapat 5 komponen kritis dan penurunan downtime sebesar 37,50\%. Reliability Centred Maintenance (RCM) adalah serangkaian proses yang digunakan untuk menentukan apa yang harus dilakukan dalam memastikan bahwa aset - aset fisik dapat berjalan dengan baik dalam menjalankan fungsi yang dikehendaki oleh pemakainya [4, 5]. Penelitian lainya tentang RCM dilakukan oleh Goodfellow [6], Bertling, et al. [7], Fischer, et al. [8], dan Asisco, et al. [9] menunjukkan bahwa RCM dapat digunakan untuk menentukan tindakan perawatan yang sesuai untuk setiap komponen mesin.

Pada penelitian terdahulu umumnya RCM digunakan menentukan tindakan perawatan yang sesuai untuk setiap komponen mesin. Namun pada penelitian ini, RCM akan di kombinasikan dengan interval penggantian komponen untuk meminimalisasi Total Minimum Downtime (TMD). Keuntungan metode RCM adalah memfokuskan tindakan perawatan pada mesin yang memiliki komponen kritis sehingga dapat mengurangi downtime. Keuntungan TMD adalah dapat mengetahui waktu yang dibutuhkan suatu komponen untuk diganti dengan downtime yang paling minimum [9]. Kerusakan yang terjadi pada mesin pendukung sistem boiler di PT. Indo Pusaka Berau mengakibatkan tingginya downtime dengan rata - rata $26,20 \%$ perbulan. Berdasarkan pada permasalahan di atas dilakukan penelitian dengan metode RCM untuk mengetahui mesin yang memiliki komponen kritis dari pendukung sistem boiler dan menentukan interval penggantian komponen mesin kritis. Dengan menggunakan metode RCM dapat menurunkan downtime yang terjadi pada PT. Indo Pusaka Berau.

\section{Metode Penelitian}

Penelitian ini digolongkan kedalam jenis penelitian deskriptif, metode yang digunakan adalah RCM (Reliability Centered Maintenance). Data - data yang dibutuhkan adalah data kerusakan mesin pada sistem boiler, data waktu antar kerusakan komponen mesin sistem boiler. Pemilihan mesin yang paling kritis digambarkan dengan diagram pareto [10]. Metode RCM digunakan untuk menentukan komponen kritis yang terdapat pada mesin - mesin di sistem boiler PT. Indo Pusaka Berau. Metode RCM terdiri dari tujuh langkah diantaranya, pemilihan sistem dan pengumpulan informasi, batasan sistem, deskripsi sistem dan blok diagram fungsi, fungsi sistem dan kegagalan fungsi, failure mode and effect analysis (FMEA), logic tree analysis (LTA), pemilihan tindakan [5]. Selanjutnya dilakukan perhitungan interval penggantian komponen dengan tahapan pengujian distribusi, reliability dari waktu antar kerusakan komponen mesin kritis dan Perhitungan interval penggantian komponen kritis dengan Total Minimum Downtime (TMD)[5].

\section{Hasil dan Pembahasan}

\subsection{Identifikasi Mesin Kritis Dengan Diagram Pareto}

Berdasarkan Gambar 1 mesin sootblower superheater memiliki presentase frekuensi kerusakan 42,86\%, sehingga mesin sootblower superheater yang dipilih untuk dilakukan perawatan. 


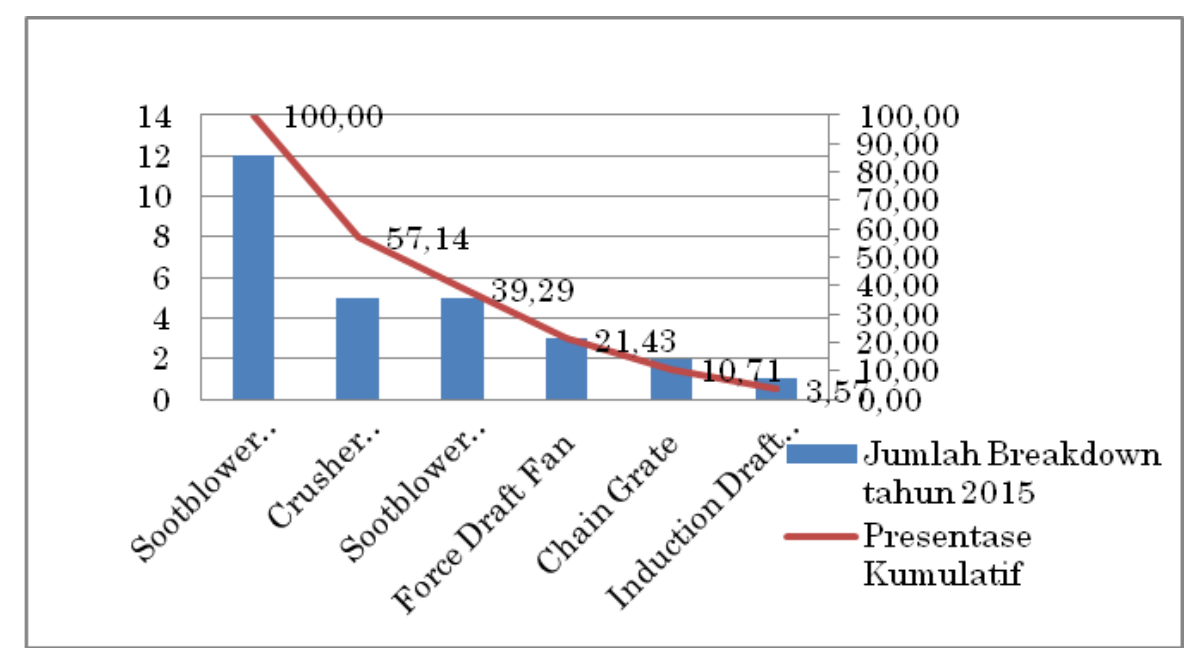

Gambar 1 Diagram Pareto Breakdown Mesin Pt Indo Pusaka Berau

\subsection{Reliability Centered Maintenance (RCM)}

Ada tujuh langkah dalam metode RCM, yaitu:

1. Pemilihan sistem dan pengumpulan informasi

Proses analisis RCM dilakukan pada level unit proses bukan pada level komponen. Sistem yang dipilih pada penelitian ini yaitu sistem boiler.

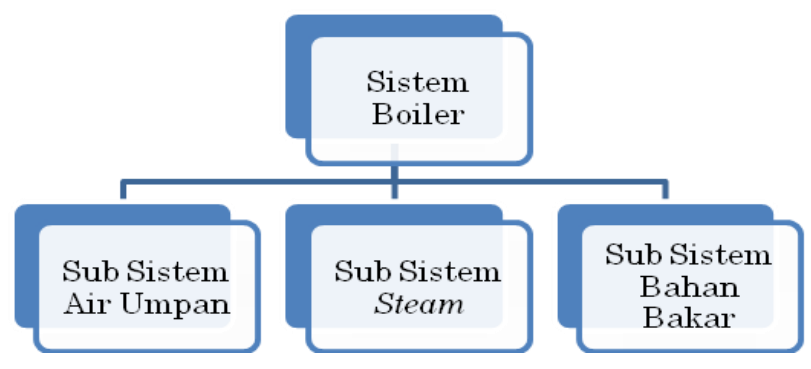

Gambar 2 Sistem Boiler

Pada Gambar 2 tidak semua dilakukan proses analisis, disebabkan apabila dilakukan analisis 3 sub sistem maka sangat luas. Sehingga analisis dilakukan pada sub sistem bahan bakar, karena dianggap mesin dengan tingkat kerusakan tertinggi.

2. Batasan Sistem

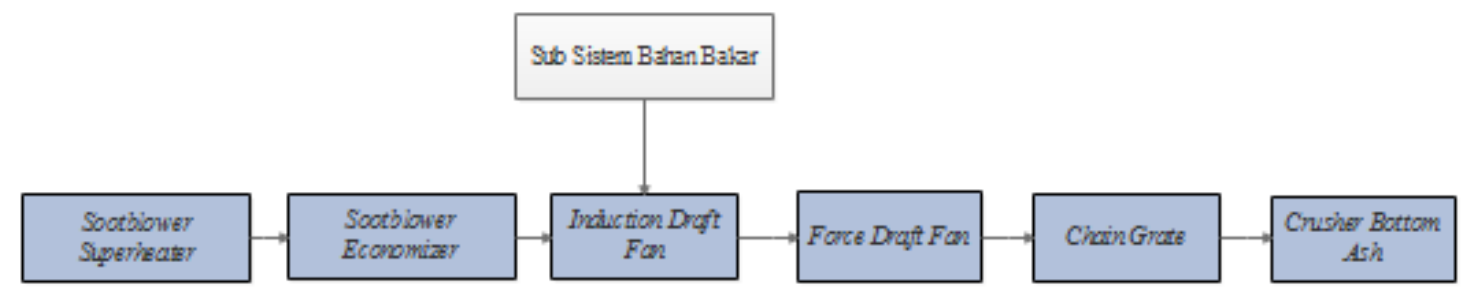

Gambar 3 Sub Sistem Bahan Bakar

Batasan sistem pada penelitian ini adalah membahas tentang sub sistem bahan bakar pada sistem boiler. Batasan sistem dapat dilihat pada Gambar 3. 
3. Deskripsi Sistem dan Blok Diagram Fungsi

Deskripsi sistem dari sub sistem bahan bakar terbagi atas sootblower superheater, sootblower economizer, induction draft fan, force draft fan, chain grate, crusher bottom ash. Blok diagram fungsi dilakukan pada mesin sootblower superheater. Penyusunan System Work Breakdown System (SWBS) merupakan struktur yang menjabarkan komponen - komponen yang berhubungan dengan fungsi sistem yang mengalami breakdown. SWBS Mesin Sootblower Superheater dapat dilihat pada Tabel 1.

Tabel 1 SWBS Mesin Sootblower Superheater

\begin{tabular}{cccc}
\hline Kode & Mesin & Kode & Komponen \\
\hline $\mathrm{A}$ & Sootblower Superheter & A1 & Gland Seal Steam \\
& A2 & Check Valve \\
& A3 & El Bow \\
\hline
\end{tabular}

4. Fungsi Sistem dan Kegagalan Fungsi

Berdasarkan kode - kode yang terdapat pada System Work Breakdown System (SWBS) maka dibuat fungsi sistem dan kegagalan fungsi dapat dilihat pada Tabel 2.

Tabel 2 Fungsi Sistem dan Kegagalan Fungsi

\begin{tabular}{|c|c|c|}
\hline No Fungsi & No Fungsi Kerusakan & $\begin{array}{c}\text { Uraian Fungsi/Kegagalan } \\
\text { Fungsi }\end{array}$ \\
\hline \multirow[t]{2}{*}{ A. 1} & & $\begin{array}{l}\text { Menutup kebocoran uap, } \\
\text { khususnya pada sootblower }\end{array}$ \\
\hline & A.1.1 & $\begin{array}{c}\text { Gland seal rusak akibatnya uap } \\
\text { banyak yang keluar dari } \\
\text { sootblower }\end{array}$ \\
\hline \multirow[t]{2}{*}{ A. 2} & & $\begin{array}{l}\text { Membuat aliran steam menajad } \\
\text { satu arah pada sootblower }\end{array}$ \\
\hline & A.2.1 & $\begin{array}{c}\text { Check valve tidak dapat } \\
\text { mengalirkan steam sehingga } \\
\text { menyambut aliran steam ke } \\
\text { sootblower }\end{array}$ \\
\hline \multirow[t]{2}{*}{ A.3 } & & Mengubah arah/aliran steam \\
\hline & A.3.1 & $\begin{array}{c}\text { Elbow rusak terjadi kebocoran } \\
\text { sehingga aliran steam menjadi } \\
\text { tindak lancar }\end{array}$ \\
\hline
\end{tabular}

\section{Failure Mode and Effect Analysis (FMEA)}

FMEA dapat menggambarkan tingkat keseringan kejadian kerusakan, keparahan dan tingkat deteksi dinyatakan dengan nilai RPN (Risk Priority Number), merupakan produk matematis dari keseriusan severity, occurance, detection. Hasil FMEA dapat dilihat pada Tabel 3.

\section{Logic Tree Analysis (LTA)}

Tujuan untuk memberikan prioritas pada tiap mode kerusakan dan melakukan tinjauan dan fungsi, sehingga tiap mode kegagalan tidak sama dalam prioritasnya. Dapat dilihat pada Tabel 4 untuk mesin Sootblower Superheater. 
Berdasarkan Tabel 4 komponen gland seal steam dan check valve masuk dalam kategori B (outage problem) yaitu komponen yang dapat mengakibatkan kegagalan pada seluruh atau sebagian sistem. komponen $E l$ bow masuk dalam kategori C (economic problem) yaitu komponen yang dapat tidak menyebabkan kegagalan pada seluruh atau sebagian sistem tetapi menyebabkan kerugian pada perusahaan karena fungsi komponen berkurang.

Tabel 3 FMEA Untuk Setiap Komponen

\begin{tabular}{|c|c|c|c|c|c|c|c|c|}
\hline Subsistem & No & Komponen & $\begin{array}{l}\text { Failure } \\
\text { Mode }\end{array}$ & Failure Causes & Failure Effect & $\bar{S}$ & $\mathrm{O}$ & D \\
\hline \multirow[t]{3}{*}{$\begin{array}{l}\text { Sootblower } \\
\text { superheater }\end{array}$} & 1 & $\begin{array}{l}\text { Gland Seal } \\
\text { Steam }\end{array}$ & $\begin{array}{l}\text { Gland } \\
\text { Seal } \\
\text { Rusak }\end{array}$ & $\begin{array}{l}\text {-Waktu pakai } \\
\text { yang sudah habis } \\
\text { - Mendapat } \\
\text { tekanan steam } \\
\text { yang tinggi } \\
\text { - Pemasangan yg } \\
\text { tidak tepat }\end{array}$ & $\begin{array}{l}\text { Terjadi } \\
\text { kebocoran } \\
\text { sehingga steam } \\
\text { banyak keluar }\end{array}$ & $\overline{9}$ & 4 & 5 \\
\hline & 2 & Check Valve & $\begin{array}{l}\text { Check } \\
\text { Valve } \\
\text { rusak }\end{array}$ & $\begin{array}{l}\text { Waktu } \\
\text { pengoperasian } \\
\text { dengan tekanan } \\
\text { steam yang tinggi }\end{array}$ & $\begin{array}{l}\text { Terjadi } \\
\text { penyumbatan }\end{array}$ & 10 & 4 & 3 \\
\hline & 3 & El Bow & $\begin{array}{l}\text { El Bow } \\
\text { rusak }\end{array}$ & $\begin{array}{l}\text {-Umur el bow } \\
\text { habis } \\
\text { - pemasangan } \\
\text { yang tidak tepat }\end{array}$ & $\begin{array}{l}\text { Kebocoran pada } \\
\text { pipa sootblower }\end{array}$ & 8 & 2 & 6 \\
\hline
\end{tabular}

Tabel 4 Logic Tree Analysis Untuk Setiap Komponen

\begin{tabular}{cc}
\hline Komponen & Critical Analysis Category \\
\hline Gland seal steam & $\mathrm{B}$ \\
Check valve & $\mathrm{B}$ \\
El bow & $\mathrm{C}$ \\
\hline
\end{tabular}

\section{Pemilihan Tindakan}

Pemilihan tindakan merupakan tahap terakhir dari proses RCM. Pada proses ini akan menentukan tindakan yang tepat untuk mode kerusakan tertentu. Penyusunan pemilihan tindakan untuk komponen mesin sootblower superheater. Diperoleh 2 komponen yang masuk time directed yaitu gland seal steam dan check valve, tindakan yang diambil lebih berfokus pada aktivitas pergantian yang dilakukan secara berkala. Dan 1 komponen masuk kedalam condition directed yaitu el bow, tindakan yang diambil bertujuan untuk mendeteksi kerusakan dengan cara memeriksa alat. Apabila ditemukan gejala - gejala kerusakan peralatan maka dilanjutkan dengan perbaikan atau penggantian komponen.

\subsection{Uji Distribusi}

Perhitungan reliability dilakukan pada komponen yang termasuk dalam pemilihan tindakan time directed (TD). komponen tersebut yaitu check valve dan gland seal steam. Pengujian pola distribusi ini menggunakan software easy fit 5.6 professional dengan goodness of fit yang digunakan adalah kolomogorv smirnov. Parameter - parameter 
yang dihasilkan digunakan untuk perhitungan Total Minimum Downtime (TMD). Dapat dilihat pada Tabel 5 hasil dari uji distribusi menggunakan software easy fit 5.6. professional.

Tabel 5 Uji Distribusi Dengan Software Easy Fit 5.6. Professional.

\begin{tabular}{cccc}
\hline No & Komponen & Pola Distribusi & Parameter \\
\hline $\mathbf{1}$ & Gland Seal Steam & Normal & $\sigma=17,014 \mu=59,667$ \\
$\mathbf{2}$ & Check Valve & Normal & $\sigma=28,417 \mu=71$ \\
\hline
\end{tabular}

\subsection{Perhitungan Total Minimum Downtime (TMD)}

Total Minimum Downtime adalah waktu yang dibutuhkan suatu komponen untuk diganti dengan komponen lain yang membuthkan waktu downtime yang paling minimum. Komponen gland seal steam diambil contoh dalam perhitungan.

1. Perhitungan fungsi distribusi kumulatif komponen gland seal steam

Jenis distribusi : Normal

Parameter $\quad: \sigma=17,014 \mu=59,667$

Fungsi distribusi kumulatif untuk normal adalah:

$$
\begin{aligned}
& \mathrm{F}(\mathrm{t})=\frac{1}{\sigma \sqrt{2 \pi}} \int_{t}^{t+1} \exp \left(-\frac{[\mathrm{t}-\mu]^{2}}{2 \sigma^{2}}\right) d t \\
& \mathrm{~F}(1)=\frac{1}{17,014 \sqrt{2 \pi}} \int_{t}^{t+1} \exp \left(-\frac{[1-59,667]^{2}}{2(17,014)^{2}}\right) d t \\
& \mathrm{~F}(2)=\frac{1}{17,014 \sqrt{2 \pi}} \int_{t}^{t+1} \exp \left(-\frac{[2-59,667]^{2}}{2(17,014)^{2}}\right) d t
\end{aligned}
$$

2. Menghitung interval kerusakan tiap waktu.

$\mathrm{H}(0)$ selalu ditetapkan $=0$

$$
\begin{aligned}
\mathrm{H}(\mathrm{t}) & =\sum_{t=0}^{t-1}[1+H(t-i-1)] \int_{t}^{t+1} f(t) \\
& =0 \\
\mathrm{H}(1) & =[1+\mathrm{H}(0)] \mathrm{x} \int_{0}^{1} f(0) \\
& =(1+0) 0 \\
& =0 \\
\mathrm{H}(2) & =[1+\mathrm{H}(1)] \times \int_{0}^{1} f(0)+[1+\mathrm{H}(0)] \mathrm{x} \int_{1}^{2} f(1) \\
& =(1+0) 0+(1+0) \\
& =1
\end{aligned}
$$


3. Perhitungan total minimum downtime (TMD)

Dengan rumus :

$$
\begin{aligned}
\mathrm{D}(\mathrm{tp}) & =\frac{H(\mathrm{tp}) \mathrm{Tf}+\mathrm{Tp}}{\mathrm{tp}+\mathrm{Tp}} \\
\mathrm{D}(0) & =\frac{(0)(0,125)+(0,0416)}{0+0,0416} \\
& =1 \\
\mathrm{D}(1) & =\frac{(0)(0,125)+(0,0416)}{1+0,0416} \\
& =0,039939 \\
\mathrm{D}(2) & =\frac{\left(6,804^{-5}\right)(0,125)+(0,0416)}{2+0,0416}
\end{aligned}
$$

Jadwal penggantian dilakukan dengan perhitungan interval pergantian komponen - komponen dengan pendekatan TMD. Dari Tabel 6 dapat dilihat jadwal penggantian.

Tabel 6 Jadwal Pergantian Komponen

\begin{tabular}{ccc}
\hline No & Komponen & Interval Pergantian Optimum \\
\hline $\mathbf{1}$ & Gland Seal Steam & Pergantian komponen dilakukan setiap 37 hari \\
$\mathbf{2}$ & Check valve & Pergantian komponen dilakukan setiap 58 hari \\
\hline
\end{tabular}

Berdasarkan Tabel 6 didapatkan waktu pergantian komponen gland seal steam selama 37 hari, dan komponen check valve selama 58 hari.

\begin{tabular}{|c|c|c|c|c|c|c|}
\hline \multirow[t]{2}{*}{ No } & \multirow[t]{2}{*}{ Komponen } & \multicolumn{2}{|c|}{$\begin{array}{c}\text { Sistem Perawatan } \\
\text { Sekarang }\end{array}$} & \multicolumn{2}{|c|}{ Sistem Perawatan Usulan } & \multirow{2}{*}{$\begin{array}{c}\text { Penurunan } \\
\text { Downtime } \\
(\%)\end{array}$} \\
\hline & & $\begin{array}{c}\text { Interval } \\
\text { Pergantian } \\
\text { Komponen } \\
\text { (Hari) }\end{array}$ & $\begin{array}{l}\text { Downtime } \\
\text { (Hari) }\end{array}$ & $\begin{array}{c}\text { Interval } \\
\text { Pergantian } \\
\text { Komponen } \\
\text { (Hari) }\end{array}$ & $\begin{array}{l}\text { Downtime } \\
\text { (Hari) }\end{array}$ & \\
\hline 1 & $\begin{array}{l}\text { Gland Seal } \\
\text { Steam }\end{array}$ & 59 & 0,001740 & 37 & 0,001418 & $18.50 \%$ \\
\hline 2 & \multicolumn{5}{|c|}{ Total Penurunan Downtime Rata-Rata } & $\begin{array}{c}4,16 \% \\
\mathbf{1 1 , 3 3}\end{array}$ \\
\hline
\end{tabular}

\subsection{Penurunan Downtime Perawatan Sekarang dan Usulan}

Sistem perawatan yang diusulkan diharapkan dapat menurunkan downtime terhadap sistem boiler dari komponen mesin sootblower superheater. Pada Tabel 7 menunjukkan adanya penurunan downtime sebesar 11,33\% dari perawatan sekarang.

Tabel 7 Penurunan Downtime Perawatan Sekarang dan Usulan

\section{Simpulan}

Komponen yang paling kritis berdasarkan nilai FMEA yang memiliki Risk Priority Number (RPN) terbesar yaitu gland seal steam sebesar 180, check valve sebesar 120 sehingga membutuhkan perhatian yang lebih dan tindakan pemeliharaan yang 
tepat. Hasil pemilihan tindakan perawatan RCM terdapat satu komponen kritis yang direncanakan dengan perawatan CD (condition directed), yaitu El Bow, dan 2 komponen kritis yang direncanakan dengan perawatan TD (time directed) yaitu gland seal steam dan check valve. Interval penggantian optimum komponen dengan Total Minimum Downtime yaitu gland seal steam sebesar 37 hari dan check valve 58 hari. Dengan mengusulkan metode RCM sebagai metode perawatan. Perbandingan perawatan dapat dilihat adanya potensi penurunan rata - rata downtime sebesar 11,33\% dari perawatan yang dilakukan perusahaan sekarang dengan usulan yang dilakukan peneliti.

\section{Referensi}

[1] B. S. Dhillon, Maintainability, maintenance, and reliability for engineers: CRC Press, 2006.

[2] N. Ansori and M. I. Mustajib, "Sistem Perawatan Terpadu (Integrated Maintenance System)," Graha Ilmu, Yogyakarta, 2013.

[3] A. B. Prasetyo, "Penerapan Konsep Reliability Centered Maintenance (RCM) Pada Sistem Perawatan Mesin di PT. XYZ," 2016.

[4] F. Kimura, T. Hata, and N. Kobayashi, "Reliability-centered maintenance planning based on computer-aided FMEA," in Proc. of the 35th CIRPInternational Seminar on Manufacturing Systems, 2002, pp. 506-511.

[5] M. Rausand and J. Vatn, "Reliability centred maintenance," in Complex system maintenance handbook, ed: Springer, 2008, pp. 79-108.

[6] J. W. Goodfellow, "Applying reliability centered maintenance (RCM) to overhead electric utility distribution systems," in Power Engineering Society Summer Meeting, 2000. IEEE, 2000, pp. 566-569.

[7] L. Bertling, R. Allan, and R. Eriksson, "A reliability-centered asset maintenance method for assessing the impact of maintenance in power distribution systems," IEEE Transactions on power systems, vol. 20, pp. 75-82, 2005.

[8] K. Fischer, F. Besnard, and L. Bertling, "Reliability-centered maintenance for wind turbines based on statistical analysis and practical experience," IEEE Transactions on Energy Conversion, vol. 27, pp. 184-195, 2012.

[9] H. Asisco, K. Amar, and Y. R. Perdana, "Usulan Perencanaan Perawatan Mesin Dengan Metode Reliability Centered Maintenance (RCM) Di PT. Perkebunan Nusantara VII (Persero) Unit Usaha Sungai Niru Kab. Muara Enim," Karunia Vol VIII, pp. 78-98, 2012.

[10] R. W. Anindita, F. Arina, and P. F. Ferdinant, "Identifikasi Pola Kerusakan Komponen Kritis pada Mesin EAF dengan Simulasi Monte Carlo," Jurnal Teknik Industri Untirta, vol. 1, 2013. 